\title{
Functionalized Mesoporous Silica via an Aminosilane Surfactant Ion Exchange Reaction: Controlled Scaffold Design and Nitric Oxide Release
}

\author{
Robert J. Soto, Lei Yang, and Mark H. Schoenfisch* \\ Department of Chemistry, University of North Carolina at Chapel Hill, CB3290, Chapel Hill, North Carolina 27599, United States
}

Supporting Information

\begin{abstract}
Nitric oxide-releasing mesoporous silica nanoparticles (MSNs) were prepared using an aminosilane-template surfactant ion exchange reaction. Initially, bare silica particles were synthesized under basic conditions in the presence of cetyltrimethylammonium bromide (CTAB). These particles were functionalized with nitric oxide (NO) donor precursors (i.e., secondary amines) via the addition of aminosilane directly to the particle sol and a commensurate ion exchange reaction between the cationic aminosilanes and CTAB. N-Diazeniumdiolate NO donors were formed at the secondary amines to yield NO-releasing MSNs. Tuning of the ion exchange-based MSN modification approach allowed for the preparation of monodisperse particles ranging from 30 to $1100 \mathrm{~nm}$. Regardless of size, the MSNs stored appreciable levels of NO $\left(0.4-1.5 \mu \mathrm{mol} \mathrm{mg} \mathrm{mg}^{-1}\right)$ with tunable NO release durations $(1-33 \mathrm{~h})$ dependent on the aminosilane modification. Independent control of NO release properties and particle size was achieved, demonstrating the flexibility of this novel MSN synthesis over conventional co-condensation and surface grafting strategies.
\end{abstract}

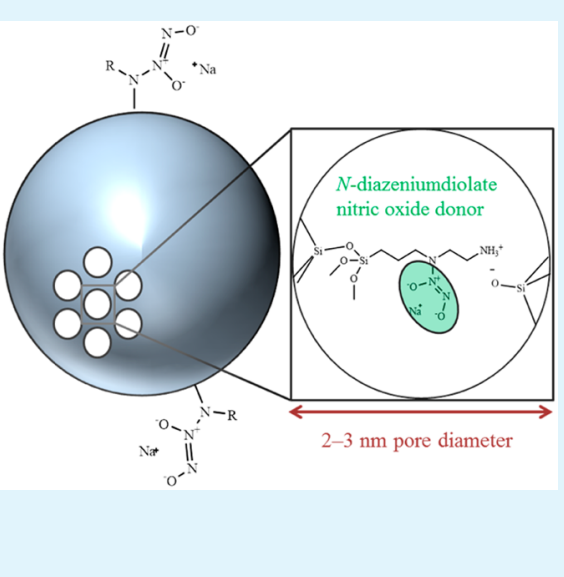

KEYWORDS: mesoporous silica, nitric oxide, $\mathrm{N}$-diazeniumdiolate, silica nanoparticle, drug release, macromolecular nitric oxide donor

\section{INTRODUCTION}

Nitric oxide (NO), an endogenous diatomic free radical, mediates multiple physiological processes, including angiogenesis, ${ }^{1}$ blood pressure regulation, ${ }^{2}$ wound healing, ${ }^{3,4}$ and the immune response. ${ }^{5,6}$ In vivo, nitric oxide synthase (NOS) enzymes generate $\mathrm{NO}$ at concentrations $(\mathrm{nM}-\mu \mathrm{M})$ and kinetics dependent on the enzyme location and purpose. ${ }^{3}$ For example, low concentrations of NO generated via calciumdependent endothelial and neuronal NOS regulate neovascularization $^{1}$ and serve roles in neurotransmission. ${ }^{7}$ Activation of the inducible NOS isoform by immunological stimuli (e.g., lipopolysaccharide, interferon- $\gamma$ ) causes sustained NO release at high concentrations to eradicate foreign pathogens as part of the innate immune response. ${ }^{5,6}$ The multifaceted roles of endogenous $\mathrm{NO}$ are attributable to precise spatiotemporal NO release by cells expressing the NOS enzymes. In addition, NOs short biological lifetime (seconds) restricts its action to $<0.5 \mathrm{~mm}$ from the point of generation. ${ }^{8}$

Because of NO's overwhelming presence in physiology, the administration of exogenous NO gas represents a potential therapy for many diseases. ${ }^{9}$ A significant body of research has focused on the development of donors that store and release NO under specific chemical conditions to address the concentration-dependent behavior of NO and avoid challenges associated with the administration of NO directly, such as the need for a pressurized gas cylinder and NO's rapid reaction in biological media. ${ }^{9}$ In particular, $\mathrm{N}$-diazeniumdiolate $\mathrm{NO}$ donors, formed by the reaction of gaseous NO with secondary amines, spontaneously release NO in physiological buffer upon reaction with hydronium ions. This class of molecules has accordingly received attention for biological applications because the breakdown of the NO donor and concomitant $\mathrm{NO}$ release occurs at rates dependent on $\mathrm{pH}$, temperature, and the chemical structure of the precursor molecule used for $\mathrm{N}$ diazeniumdiolate formation.

The potential utility of the $\mathrm{N}$-diazeniumdiolate functional group originally inspired research on low molecular weight $\mathrm{NO}$ donors. ${ }^{10,11}$ Unfortunately, limited NO capacity and duration generally preclude the use of these small molecule NO donors for therapeutic applications. For enhancement of NO storage and for exerting additional control over NO release, much work has focused on the synthesis of $\mathrm{N}$-diazeniumdiolate-modified macromolecular NO delivery scaffolds, including chitosan oligosaccharides, ${ }^{12}$ dendrimers, ${ }^{13-15}$ gold clusters, ${ }^{16,17}$ and silica nanoparticles. ${ }^{18-25}$ With respect to silica, surface grafting, ${ }^{21,26}$ co-condensation, ${ }^{20,27}$ and water-in-oil microemulsion ${ }^{19}$ methods have been used to prepare $\mathrm{N}$-diazeniumdiolate-functionalized particles. Silica is attractive as an NO release scaffold as it is well-tolerated (i.e., nontoxic) and readily implemented as a drug delivery vehicle. ${ }^{11,19,26}$ For example, NO donor-modified

Received: November 12, 2015

Accepted: December 30, 2015

Published: December 30, 2015 
Table 1. Synthesis Conditions and Nitrogen Physisorption Data for MSNs of Varying Size ${ }^{a}$

\begin{tabular}{|c|c|c|c|c|c|c|c|c|}
\hline $\begin{array}{l}\text { particle } \\
\text { size }\end{array}$ & $\begin{array}{c}{\left[\mathrm{H}_{2} \mathrm{O}\right]} \\
(\mathrm{M})\end{array}$ & $\begin{array}{c}{\left[\mathrm{NH}_{3}\right]} \\
(\mathrm{M})\end{array}$ & $\begin{array}{c}{[\mathrm{CTAB}]} \\
(\mathrm{mM})\end{array}$ & $\begin{array}{l}\text { reaction volume } \\
(\mathrm{mL})\end{array}$ & $\begin{array}{l}\text { temperature } \\
\left({ }^{\circ} \mathrm{C}\right)\end{array}$ & $\begin{array}{l}\text { specific surface area } \\
\left(\mathrm{m}^{2} \mathrm{~g}^{-1}\right)^{b}\end{array}$ & $\begin{array}{c}\text { average pore width } \\
(\AA)^{c}\end{array}$ & nitrogen wt $\%^{d}$ \\
\hline $30 \mathrm{~nm}$ & 54.5 & 0.267 & 5.30 & 150 & $68 \pm 1$ & $1290 \pm 90$ & $23.6 \pm 2.3$ & $\leq 0.01$ \\
\hline $150 \mathrm{~nm}$ & 39.4 & 0.267 & 5.30 & 150 & $38 \pm 1$ & $1170 \pm 80$ & $21.9 \pm 0.6$ & $1.11 \pm 0.12$ \\
\hline $450 \mathrm{~nm}$ & 35.0 & 0.267 & 5.30 & 150 & $23 \pm 1$ & $1280 \pm 120$ & $20.4 \pm 0.2$ & $0.13 \pm 0.06$ \\
\hline $1100 \mathrm{~nm}$ & 25.5 & 0.521 & 2.20 & 350 & $23 \pm 1$ & $1170 \pm 70$ & $19.5 \pm 0.3$ & $\leq 0.01$ \\
\hline
\end{tabular}

${ }^{a}$ Error bars represent standard deviation for $n \geq 3$ separate syntheses. ${ }^{b}$ Determined by BET analysis of the nitrogen sorption isotherms $\left(0.05 \leq \mathrm{p} / \mathrm{p}^{0}\right.$ $\leq 0.20) .{ }^{c}$ Calculated via $\mathrm{BJH}$ analysis of the nitrogen adsorption isotherm $\left(\mathrm{p} / \mathrm{p}^{0} \leq 0.60\right) .{ }^{d}$ Nitrogen wt $\%$ measured by elemental analysis.

silica particles have served as reinforcing fillers for NO-releasing polymeric coatings (i.e., for in vivo sensors) to promote angiogenesis and wound healing. ${ }^{28,29}$ Such materials have also proven effective as antimicrobial abrasives that may be integrated with oral hygiene technologies. ${ }^{18,27}$

Despite their value as potential therapeutics, current strategies for synthesizing NO-releasing silica nanoparticles remain limited by challenges associated with altering the physical properties of the particles and the NO release independent of one another. The use of mesoporous silica represents an attractive macromolecular scaffold for enhancing NO storage and release because of the inherently greater and modifiable surface area $\left(500-1,200 \mathrm{~m}^{2} \mathrm{~g}^{-1}\right)$ relative to previous nonporous silica systems. ${ }^{19-21,23,25-27}$ Control over pore formation and the silica mesophase is achieved via the synthesis of the nanoparticles around an ordered surfactant aggregate, generally an alkyltrimethylammonium salt, that serves as the structure-directing agent (SDA). ${ }^{30,31}$ Covalent attachment of secondary-amine containing silanes (i.e., NO donor precursors) to mesoporous silica is carried out by direct incorporation of the aminosilane into the particle backbone via co-condensation $^{32-34}$ or postsynthetically through surface grafting. ${ }^{35-37}$ In the co-condensation approach, Coulombic repulsion between the cationic surfactant molecules and the protonated backbone amines destabilizes the template, resulting in materials with irregular morphology, even at low aminosilane concentrations. ${ }^{32,38}$ Postsynthetic surface grafting (after extracting the SDA) is generally the preferred method for functionalizing mesoporous silica, albeit at the cost of a multistep workflow and loss of control over the amount of aminosilane incorporated. Moreover, the grafting process requires a nonpolar aprotic solvent to avoid irreversible water-induced particle agglomeration, ${ }^{25}$ often resulting in heterogeneous amine distribution and batch-to-batch irreproducibility. ${ }^{37}$

Ion exchange between cationic organosilanes and common alkyltrimethylammonium SDAs represents a new MSN functionalization approach. To date, this strategy has been limited to postsynthetic modification in organic solvent, raising concerns regarding synthesis irreproducibility that is a similar detriment to the surface grafting approach. Herein, we report aminosilane ion exchange with cetyltrimethylammonium bromide $(\mathrm{CTAB})$ in the aqueous particle solution. Initially, we prepare a diverse selection of monodisperse NO-releasing amine-functionalized mesoporous silica nanoparticles (MSNs). The surface- and pore-bound secondary amines are then converted to $\mathrm{N}$-diazeniumdiolate moieties to yield the NOreleasing MSNs. Using the aqueous ion exchange approach, we demonstrate autonomous control over particle size and NO release capabilities (i.e., NO release rates and total NO storage), representing a significant advantage over conventional co-condensation and grafting methods. The relationship between NO release kinetics and particle mesophase ordering is also elucidated via detailed physicochemical analysis of the MSNs.

\section{EXPERIMENTAL SECTION}

Materials. Tetraethylorthosilicate (TEOS), 3-aminopropyltriethoxysilane (APTES), 3-mercaptopropyltrimethoxysilane (MPTMS), 3(trimethoxysilylpropyl)diethylenetriamine (DET3), N-methylaminopropyltrimethoxysilane (MAP3), $N$-(6-aminohexyl)aminopropyltrimethoxysilane (AHAP3), N-(2-aminoethyl)-3-aminopropyltrimethoxysilane (AEAP3), and isobutyltrimethoxysilane (BTMS) were purchased from Gelest (Morrisville, PA) and stored under a nitrogen atmosphere. Sodium methoxide (NaOMe; 5.4 M in methanol), anhydrous $\mathrm{N}, \mathrm{N}$-dimethylformamide (DMF), anhydrous methanol $(\mathrm{MeOH})$, ethanol (EtOH), aqueous ammonium hydroxide (30 wt \%; $\left.\mathrm{NH}_{4} \mathrm{OH}\right)$, concentrated hydrochloric acid $(\mathrm{HCl})$, and all salts were purchased from Fisher Scientific (Fair Lawn, NJ). Cetyltrimethylammonium bromide was purchased from Sigma (St. Louis, $\mathrm{MO}$ ). Nitrogen $\left(\mathrm{N}_{2}\right)$, argon (Ar), and nitric oxide (NO) calibration (25.87 ppm in nitrogen) gases were purchased from Airgas National Welders (Raleigh, NC). Pure NO gas was purchased from Praxair (Danbury, CT). Water was purified using a Millipore Milli-Q UV Gradient A10 system (Bedford, MA) to a resistivity of $18.2 \mathrm{M} \Omega$ $\mathrm{cm}$ and a total organic content of $\leq 10 \mathrm{ppb}$. Unless specified, all chemicals were used as received without further purification.

Nanoparticle Synthesis. Particle synthesis was achieved by addition of tetraethylorthosilicate as a bolus to a stirred solution of water, $\mathrm{EtOH}, \mathrm{NH}_{4} \mathrm{OH}$, and $\mathrm{CTAB}$, allowing the reaction to proceed for $2 \mathrm{~h}$. For synthesis of the 30,150, and $450 \mathrm{~nm}$ diameter particles, $2.500 \mathrm{~mL}$ of TEOS in EtOH $(0.88,1.06$, and $1.33 \mathrm{M}$, respectively) was added to the reaction mixture, whereas $1.395 \mathrm{~mL}$ of concentrated TEOS was used for the synthesis of the larger $1100 \mathrm{~nm}$ particles. Synthesis conditions for the MSNs are provided in Table 1. In all cases, reaction solutions appeared turbid within $15 \mathrm{~min}$ of silane introduction. Following particle formation, additional organosilane (AEAP3, AHAP3, APTES, BTMS, MAP3, MPTMS, or DET3) was introduced directly to the colloidal solution dropwise for $5 \mathrm{~min}$ using a Kent Scientific Genie Plus syringe pump (Torrington, CT). The reaction was then aged overnight $(\sim 18 \mathrm{~h})$ with stirring. Unless specified, an optimized TEOS:organosilane molar ratio of 1.56:1.00 was used. Following functionalization, particles were collected by centrifugation $\left(6540 \mathrm{~g}, 4{ }^{\circ} \mathrm{C}, 15 \mathrm{~min}\right)$, washed three times with EtOH, and dried under vacuum. For both the 30 and $150 \mathrm{~nm}$ particles, $\mathrm{EtOH}$ (one volume per two volumes of the reaction mixture) was added to the solution to induce particle flocculation during the collection procedure and enhance the overall yield. Bare MSNs were synthesized and collected similarly but without the organosilane functionalization step.

Following MSN synthesis, residual CTAB was removed by ion exchange with hydrochloric acid $(\mathrm{HCl})$. Particles $(\sim 200 \mathrm{mg})$ were suspended in $30 \mathrm{~mL}$ of $10 \% \mathrm{v} / \mathrm{v} \mathrm{HCl}$ in $\mathrm{EtOH}$, agitated in an ultrasonicator bath for $30 \mathrm{~min}$, and collected by centrifugation $(6540 \mathrm{~g}$, $\left.4{ }^{\circ} \mathrm{C}, 15 \mathrm{~min}\right)$. This process was repeated three times to ensure complete CTAB removal followed by two additional $\mathrm{EtOH}$ washes. The particles were dried under vacuum to yield the surfactant-free nanoparticles. Typical yields for the amine-modified 30, 150, 450, and $1100 \mathrm{~nm}$ MSNs were 150, 175, 275, and $650 \mathrm{mg}$, respectively.

Mesoporous Silica Nanoparticle Characterization. Particle morphology was characterized using a JEOL 2010F transmission 

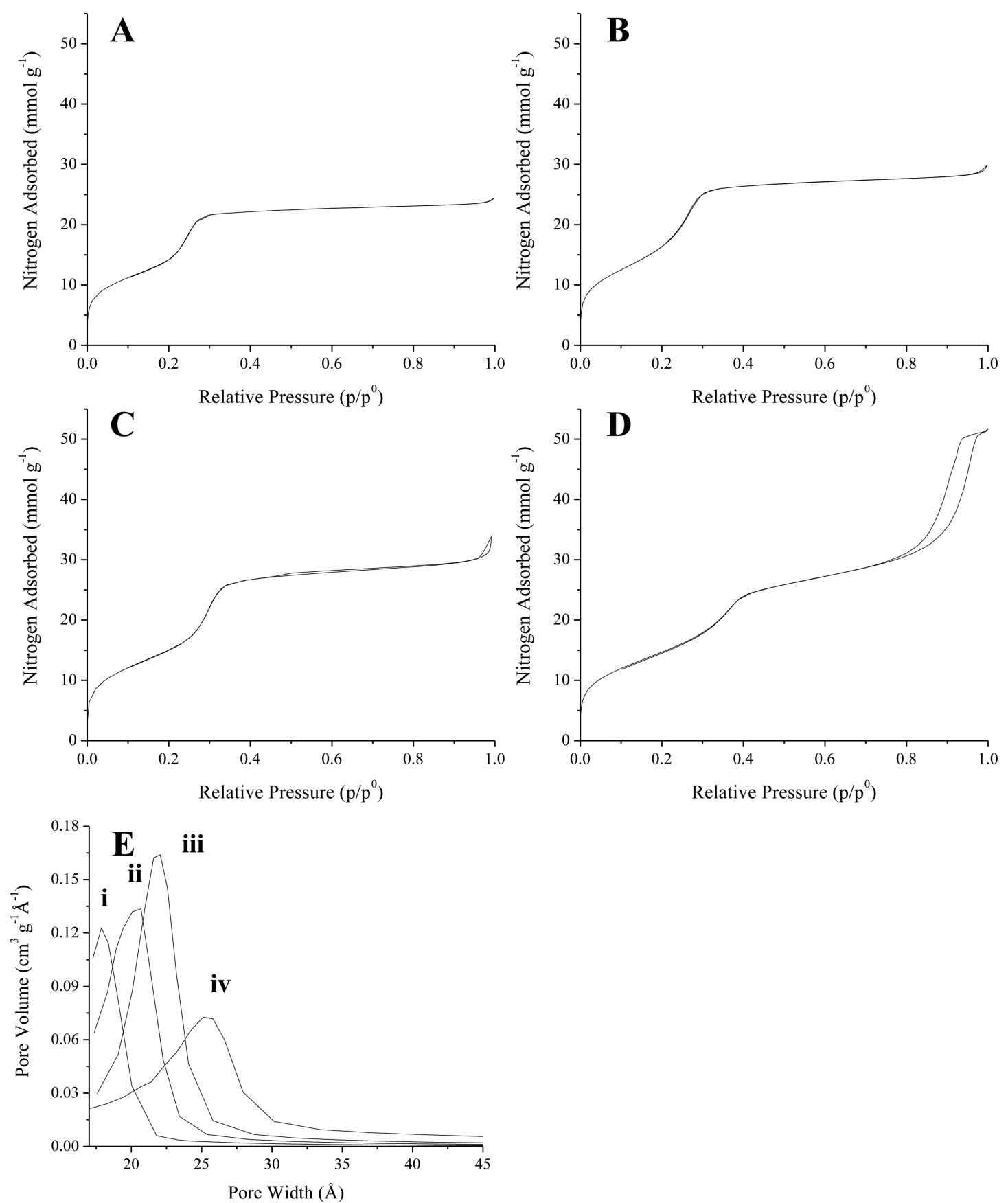

Figure 1. Nitrogen adsorption and desorption isotherms for bare (A) 1100, (B) 450, (C) 150, and (D) 30 nm MSNs. The estimated pore width distributions calculated via BJH analysis of the adsorption branch are presented in (E) for the (i) 1100, (ii) 450, (iii) 150, and (iv) $30 \mathrm{~nm}$ particles.

electron microscope (Peabody, MA). Particles were suspended in $\mathrm{MeOH}$ at $1 \mathrm{mg} \mathrm{mL} \mathrm{mL}^{-1}$ via brief agitation with an ultrasonicator. Subsequently, $5 \mu \mathrm{L}$ of the resulting dispersion was cast onto a Formvar-coated copper grid (Ted Pella, Inc.; Redding, CA). The geometric size distribution of the particles was estimated from the electron micrographs using ImageJ software (Bethesda, MD). The solution-phase behavior of the nanoparticles in water was investigated using dynamic light scattering (Malvern Zetasizer Nano-ZS; Westborough, MA) to determine MSN hydrodynamic diameter (Z-average size) and polydispersity index. Aqueous colloidal nanoparticle suspensions were prepared by dispersing particles at a concentration of $0.5 \mathrm{mg} \mathrm{mL}^{-1}$ via probe sonication at $7 \mathrm{~W}$ for $45 \mathrm{~s}$ using a Misonix S4000 ultrasonicator (Farmingdale, NY). Nitrogen sorption isotherms were collected on a Micromeritics Tristar II 3020 surface area and porosity analyzer (Norcross, GA). Samples were dried under a stream of $\mathrm{N}_{2}$ gas at $110{ }^{\circ} \mathrm{C}$ overnight and then degassed for $2 \mathrm{~h}$ prior to analysis. Brunauer-Emmett-Teller (BET) analysis of physisorption data was used to calculate MSN specific surface area for $\mathrm{p} / \mathrm{p}^{0}$ values of 0.05-0.20. Pore size analysis using the adsorption branch of the sorption isotherm $\left(0.05<\mathrm{p} / \mathrm{p}^{0}<0.60\right)$ was accomplished using the Barrett-Joyner-Halenda (BJH) method. Data obtained at relative pressures $>0.60 \mathrm{p} / \mathrm{p}^{0}$ were not considered for pore size determination as nitrogen capillary condensation occurred in the interparticle volumes for the 30 and $150 \mathrm{~nm}$ particles, inflating the calculated pore width. Pore structure/ordering information was obtained by small-angle X-ray scattering analysis of the dry MSN powder. The $\mathrm{Cu}$ $\mathrm{K} \alpha$ line $(1.54 \AA)$ was used as the source radiation, and scattering profiles were collected on a SAXSLab Ganesha point collimated pinhole system equipped with a moveable Dectris Pilatus $300 \mathrm{~K} 2$ dimensional single-photon-counting detector (Northampton, MA). 
Table 2. Characterization of AEAP3-Modified $1100 \mathrm{~nm}$ Mesoporous Silica Particles as a Function of Reaction Aminosilane Concentration $^{a}$

$\begin{array}{ccccc}\text { [AEAP3] }(\mathrm{mM}) & \text { specific surface area }\left(\mathrm{m}^{2} \mathrm{~g}^{-1}\right)^{b} & \text { cumulative pore volume }\left(\mathrm{cm}^{3} \mathrm{~g}^{-1}\right)^{c} & \text { average pore width }(\AA)^{c} & \text { nitrogen wt \% }{ }^{d} \\ 0 & 1200 \pm 70 & 0.47 \pm 0.09 & 19.5 \pm 0.3 & \leq 0.01 \\ 1.4 & 790 \pm 60 & 0.13 \pm 0.02 & 19.4 \pm 0.7 & 2.41 \pm 0.25 \\ 2.9 & 520 \pm 130 & 0.05 \pm 0.01 & 20.0 \pm 0.7 & 3.38 \pm 0.41 \\ 5.7 & 5 \pm 1 & 0.01 \pm 0.00 & 20.7 \pm 2.0 & 4.38 \pm 0.33 \\ 11.5 & 3 \pm 1 & 0.00 \pm 0.00 & \text { N.D. }{ }^{e} & 4.87 \pm 0.04\end{array}$

${ }^{a}$ Error bars represent standard deviation for $n \geq 3$ separate syntheses. ${ }^{b}$ Determined by BET analysis of the nitrogen sorption isotherms $\left(0.05 \leq \mathrm{p} / \mathrm{p}^{0}\right.$ $\leq 0.20) .{ }^{c}$ Calculated via BJH analysis of the nitrogen adsorption isotherm $\left(\mathrm{p} / \mathrm{p}^{0} \leq 0.60\right) .{ }^{d}$ Nitrogen wt $\%$ measured by elemental analysis. ${ }^{e}$ Pore width could not be calculated from the adsorption isotherm.

Scattering vector $(\mathrm{q})$ calibration was accomplished using the first-order ring for silver behenate, and data was collected for q-values of 0.005$0.724 \AA^{-1}$. Covalent incorporation of aminosilanes into the MSN backbone was confirmed via solid-state cross-polarization/magic angle spinning (CP/MAS) ${ }^{29} \mathrm{Si}$ nuclear magnetic resonance spectroscopy using a Bruker DMX 360 wide-bore spectrometer at a resonance frequency of $71.548 \mathrm{~Hz}$. Samples were carefully ground in a mortar and pestle, packed into a $4 \mathrm{~mm} \mathrm{ZrO}_{2}$ rotor, and spun at $10 \mathrm{kHz}$. All chemical shifts were determined relative to an external tetramethylsilane standard. Elemental analysis was used to quantify the nitrogen weight percent of particles before and after functionalization with secondary amine-containing silanes using a PerkinElmer 2400 CHNS/ $\mathrm{O}$ analyzer (Waltham, MA) operated in CHN mode.

$N$-Diazeniumdiolate Modification and Nitric Oxide Release Measurements. The aminosilane-modified MSNs $(\sim 15 \mathrm{mg})$ were suspended in 9:1 DMF:MeOH at $5 \mathrm{mg} \mathrm{mL}^{-1}$ in a glass vial and dispersed by ultrasonication for $20 \mathrm{~min}$. After forming a homogeneous particle dispersion, $\mathrm{NaOMe}(5.4 \mathrm{M}$ in $\mathrm{MeOH}$; $9.0 \mu \mathrm{mol}$ per mg MSN) was added to the solution and mixed. The MSN-containing vials were equipped with stir bars, placed in a stainless steel reaction bottle (Parr Instrument Co.; Moline, IL), and connected to an in-house NO reactor. The Parr bottle was flushed six times (three rapid, three 10 min) with 8 bar Ar gas to remove atmospheric oxygen and minimize the formation of NO byproducts. The vessel was subsequently pressurized with 10 bar NO gas, and the reaction proceeded for $72 \mathrm{~h}$. Of note, the $\mathrm{NO}$ gas used for $\mathrm{N}$-diazeniumdiolate formation was purified over solid potassium hydroxide for at least $4 \mathrm{~h}$ prior to reaction. After $72 \mathrm{~h}$, the Parr bottle was vented, and the vessel was flushed six more times (three short, three $10 \mathrm{~min}$ ) to remove unreacted NO. The particles were again collected by centrifugation $\left(6540 \mathrm{~g}, 4{ }^{\circ} \mathrm{C}, 15 \mathrm{~min}\right.$ ), washed three times with $\mathrm{EtOH}$, and dried under vacuum for $1-2 \mathrm{~h}$. The resulting $\mathrm{N}$-diazeniumdiolate-modified particles were stored in a vacuum-sealed bag at $-20{ }^{\circ} \mathrm{C}$ until further use.

Nitric oxide release measurements were carried out using a Sievers 280i NO analyzer (Boulder, CO). Generation of NO from the protonlabile $\mathrm{N}$-diazeniumdiolate $\mathrm{NO}$ donors was detected indirectly via chemiluminescence from excited state nitrogen dioxide formed upon the reaction of NO with ozone. The NOA was calibrated using a twopoint linear calibration; air passing through a Sievers NO zero filter served as the blank value, and $25.87 \mathrm{ppm}$ of $\mathrm{NO}$ in $\mathrm{N}_{2}$ was used as the second calibration point. Particles $(\sim 1 \mathrm{mg})$ were added to the NOA sample flask containing $30 \mathrm{~mL}$ of deoxygenated phosphate buffered saline (PBS, $0.010 \mathrm{M}, \mathrm{pH} 7.41)$ at $37{ }^{\circ} \mathrm{C}$. A stream of $\mathrm{N}_{2}$ gas $(80 \mathrm{~mL}$ $\mathrm{min}^{-1}$ ) was continuously bubbled through solution to carry liberated NO to the analyzer. Supplemental nitrogen flow was provided to the flask to match the instrument collection rate of $200 \mathrm{~mL} \mathrm{~min}{ }^{-1}$. Instantaneous NO concentrations were measured at a sampling frequency of $1 \mathrm{~Hz}$, providing near real-time information regarding MSN NO release kinetics. The NO measurements were terminated when NO release from the particles was below $10 \mathrm{ppb} \mathrm{mg}^{-1}$.

Statistical Analysis. One-way analysis of variance was used for multiple comparisons of MSN physicochemical properties (e.g., surface area, pore size, NO-release total amounts, NO-release kinetics) with provided $p$-values. Individual comparisons were carried out using a two-tailed Student's $t$ test with $\alpha=0.05$ considered as the threshold for statistical significance. All results presented represent data from three or more separate synthesis experiments.

\section{RESULTS AND DISCUSSION}

The synthesis of NO-releasing nanoparticles has been previously reported ${ }^{18-27}$ but without autonomous control over particle size, NO release kinetics, and NO storage. Generally, total NO storage for silica-based materials is limited to $<0.40 \mu \mathrm{mol} \mathrm{mg}{ }^{-1}$ due to low aminosilane incorporation. Limited NO storage often is further compounded by a lack of morphological control and poor synthesis yields. Mesoporous silica was thus selected as a new scaffold in an attempt to exert greater control over particle NO release properties. Mesoporous silica nanoparticles were prepared via a supramolecular liquid-crystal templating approach. Cationic, amphiphilic CTAB aggregates were used as the structure-directing agent for particle synthesis. ${ }^{31}$ The synthesis of four different-sized MSNs was achieved using TEOS as the backbone silane by altering the reaction temperature and reactant concentrations (Table 1). Surfactant was removed by ion exchange in ethanolic $\mathrm{HCl}$ to yield the bare mesoporous scaffolds. Although other methods (e.g., calcination) have been used for CTAB removal, irreversible particle agglomeration often results. ${ }^{39,40}$ Surfactant removal from the MSNs after agitation in $\mathrm{HCl}$ was evaluated using elemental analysis. The measured nitrogen wt $\%$ for the bare particles was $<0.2 \%$ in all cases (indicating complete CTAB removal) with the exception of the $150 \mathrm{~nm}$ system $(\sim 1.11 \%)$. The significant nitrogen content was attributed to trapped ammonia because the low carbon content (5.48 \pm $1.00 \%)$ did not reflect the presence of CTAB ( $~ 80.3 \%$ carbon by mass). Indeed, the $150 \mathrm{~nm}$ particles had a propensity to aggregate and did not disperse into solution during the washing and $\mathrm{CTAB}$ removal processes, whereas all three remaining particle systems (e.g., 30, 450, and $1100 \mathrm{~nm}$ ) readily suspended with sonication. The heterogeneity of these wash steps is likely at fault for residual nitrogen content in the $150 \mathrm{~nm}$ MSNs.

The surface areas and pore sizes of the unmodified MSNs were calculated from the affiliated nitrogen sorption isotherms (Figure 1). Each of the physisorption isotherms exhibited steep inflections at $\sim 0.2-0.4 \mathrm{p} / \mathrm{p}^{0}$ and $>0.8 \mathrm{p} / \mathrm{p}^{0}$ corresponding to capillary condensation of nitrogen in the particle mesopores and interparticle volumes, respectively. ${ }^{41}$ All isotherms were classified as Type IV isotherms without hysteresis according to the conventions adopted by the International Union of Pure and Applied Chemistry (IUPAC). ${ }^{42}$ Nitrogen gas adsorption/ desorption on CTAB-templated mesoporous silica has consistently yielded similar results. ${ }^{43}$ Importantly, MSN surface areas calculated using the Brunauer-Emmett-Teller (BET) method exceeded $1000 \mathrm{~m}^{2} \mathrm{~g}^{-1}$ in all cases (Table 1) regardless of particle size. Average pore sizes were evaluated using 
Barrett-Joyner-Halenda (BJH) analysis of a portion of the nitrogen adsorption branch (Figure $1 \mathrm{E}$ ) and yielded calculated pore widths in the range of $19.5-23.6 \AA$, which are comparable to those reported in the literature. ${ }^{32,44,45}$

The particles were modified with secondary amines by direct organosilane addition to the reaction solution following completion of the particle synthesis reaction $(\leq 2 \mathrm{~h}$ as determined by dynamic light scattering). Residual surfactant SDA was removed in a subsequent step similar to unmodified particles. The aminosilane $N$-(2-aminoethyl)-3-aminopropyltrimethoxysilane (AEAP3) was selected to optimize this process, initially using the largest $(1100 \mathrm{~nm})$ particles. As expected, lower specific surface areas were observed due to increased particle aminosilane content (Table 2). Pore size analysis of the nitrogen adsorption isotherms indicated a clear decrease in mesopore volume with increasing AEAP3 concentration, whereas the pore width remained invariable $(p>0.50)$. At AEAP3 concentrations at or exceeding $5.7 \mathrm{mM}$, the gas sorption isotherm abruptly transitioned from a type IV to a type I isotherm (Figure S1) consistent with bound organic groups on the silica network. ${ }^{46}$

Solid-state cross-polarization $\left({ }^{1} \mathrm{H} /{ }^{29} \mathrm{Si}\right) /$ magic angle spinning (CP/MAS) nuclear magnetic resonance spectroscopy (NMR) confirmed covalent incorporation of AEAP3 into the inorganic TEOS backbone (Figure 2). ${ }^{47}$ The Q-band peaks at -94, -103,

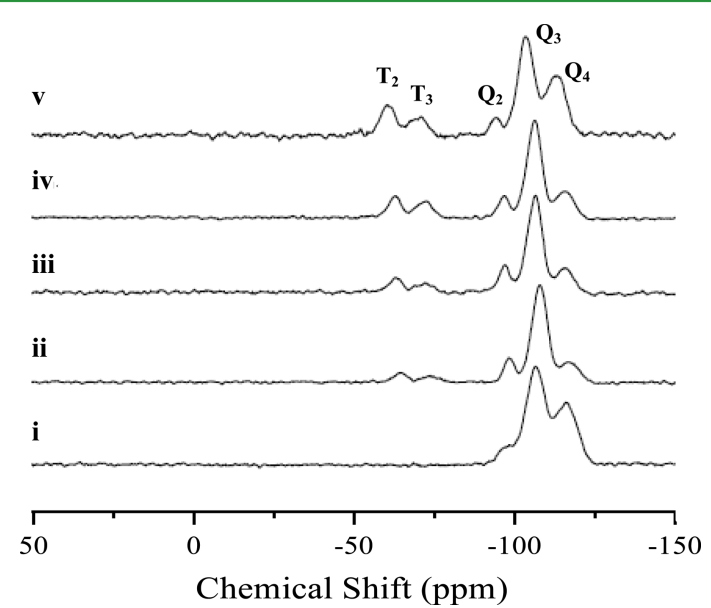

Figure 2. Solid-state CP/MAS ${ }^{29} \mathrm{Si}$ NMR spectra of $1100 \mathrm{~nm}$ MSNs at AEAP3 reaction concentrations of (i) 0.0, (ii) 1.4, (iii) 2.9, (iv) 5.7, and (v) $11.5 \mathrm{mM}$.

and $-112 \mathrm{ppm}$ were assigned to backbone $\mathrm{Si}$ atoms present as geminal silanol $\left(Q_{2}\right)$, lone silanol $\left(Q_{3}\right)$, and siloxane $\left(Q_{4}\right)$ species, respectively. The $\mathrm{T}$-band, indicative of the bound organosilane (AEAP3), consisted of peaks at -60 and $-69 \mathrm{ppm}$ that were assigned to $\mathrm{T}_{2}$ and cross-linked $\mathrm{T}_{3}$ species, respectively. The intensity of the $\mathrm{T}$-band increased with aminosilane concentration, corresponding to progressively greater amine incorporation in the final product. However, quantitative $\mathrm{CP} / \mathrm{MAS} \mathrm{NMR}$ analysis was not pursued due to signal intensity dependence on the location of ${ }^{1} \mathrm{H}$ atoms relative to ${ }^{29} \mathrm{Si}$. Interestingly, we noted a considerable amount of cross-linked $\left(\mathrm{T}_{3}\right)$ surface-bound aminosilanes that was attributed to the large water concentration $(>20 \mathrm{M})$ in the reaction mixture, driving condensation between aminosilanes. ${ }^{47}$ For comparison, MCM-41 materials produced through postsynthetic surface grafting in anhydrous solvents are primarily bidentate $T_{2}$ species and exhibit limited cross-linking $\left(\mathrm{T}_{3}\right)^{48}$

Although CP/MAS ${ }^{29} \mathrm{Si}$ NMR confirmed covalent aminosilane incorporation, elemental analysis was used as an adjunct experiment to quantitatively assess amine incorporation. As expected, nitrogen content increased with the overall reaction aminosilane concentration. At the highest AEAP3 concentration tested (11.5 mM; Table 2), a maximum nitrogen content of $4.87 \mathrm{wt} \%$ was measured. Taken together, the nitrogen sorption, NMR, and elemental analysis experiments indicated covalent incorporation of AEAP3 and suggested mesopore infiltration at aminosilane concentrations of $\leq 11.5$ $\mathrm{mM}$.

Powder small-angle X-ray scattering (SAXS) was used to gain insight into potential alterations to MSN pore structure as a function of reaction AEAP3 concentration (Figure 3). ${ }^{49}$ The SAXS profile for the bare $1100 \mathrm{~nm}$ MSNs (Figure 3) exhibited an intense scattering peak at $0.170 \AA^{-1}\left(2 \theta=2.41^{\circ}\right.$; $\left.h k l 100\right)$, and two weaker, larger-angle peaks in the scattering profile were assigned to the $110\left(0.292 \AA^{-1}\right)$ and $200\left(0.339 \AA^{-1}\right)$ reflections indexed on a hexagonal lattice (lattice constant $a$ $=43.1 \pm 1.5 \AA$ ). Although the absence of higher-order peaks indicated only modest mesoscopic ordering, the scattering profile consisted of the prominent structural lines for MCM-41type (hexagonal) silica. ${ }^{31,50-52}$ Broadening of the 100 reflection (Figure 3A) and the gradual disappearance of the $110 / 200$ scattering peaks (Figure 3B) was observed for the aminemodified MSNs (relative to the bare particles), representing a loss of long-range ordering with increasing AEAP3 concentration. These results further verify aminosilane localization within the pores.

Importantly, the particles retained excellent sphericity and monodispersity (Figure 4A) upon amine modification as indicated by transmission electron microscopy (TEM) even at the highest AEAP3 concentration presented in Table 2 (11.5 $\mathrm{mM}$ ). Undesirable particle agglomeration was routinely noted at greater AEAP3 concentrations $(\geq 14.3 \mathrm{mM})$. Interparticle bridging was occurring at these higher concentrations, revealing a practical maximum in the attainable aminosilane incorporation (Figure S2). On the basis of the results for the $1100 \mathrm{~nm}$ particles, the optimal TEOS:aminosilane molar ratio of 1.56:1.00 (corresponding to $11.5 \mathrm{mM} \mathrm{AEAP3}$ in Table 2) was used to synthesize smaller AEAP3 particles. Regardless of the intended size, this approach resulted in well-defined nanomaterials (Figure 4B-D). Dynamic light scattering (DLS) analysis of aqueous MSN dispersions (Table 3) supported TEM observations. The low observed polydispersity indices (PDIs; 0.12, 0.02, and 0.04 for the 30, 150, and $450 \mathrm{~nm}$ particles, respectively) affirmed narrow particle size distributions. The DLS/TEM data also verified covalent bonding of aminosilanes to the particle surface rather than the formation of discrete entities and likely large agglomerates. Elemental analysis (Table 3) and CP/MAS NMR (Figure S3) confirmed aminosilane incorporation with significant measured nitrogen content $(>4.50 \% \mathrm{~N})$ for each particle system.

Nitric Oxide Release. Different-sized AEAP3-modified particles were functionalized with $\mathrm{N}$-diazeniumdiolate moieties by reaction with $\mathrm{NO}$ gas at high pressure in the presence of sodium methoxide. Nitric oxide release was evaluated in realtime via chemiluminescent analysis of the NO-releasing particles in physiological buffer (PBS, $\mathrm{pH} 7.4$ ) at $37^{\circ} \mathrm{C}$ (Table 4). Upon immersion into aqueous solution, the AEAP3/ NO MSNs were characterized by a large instantaneous NO flux 

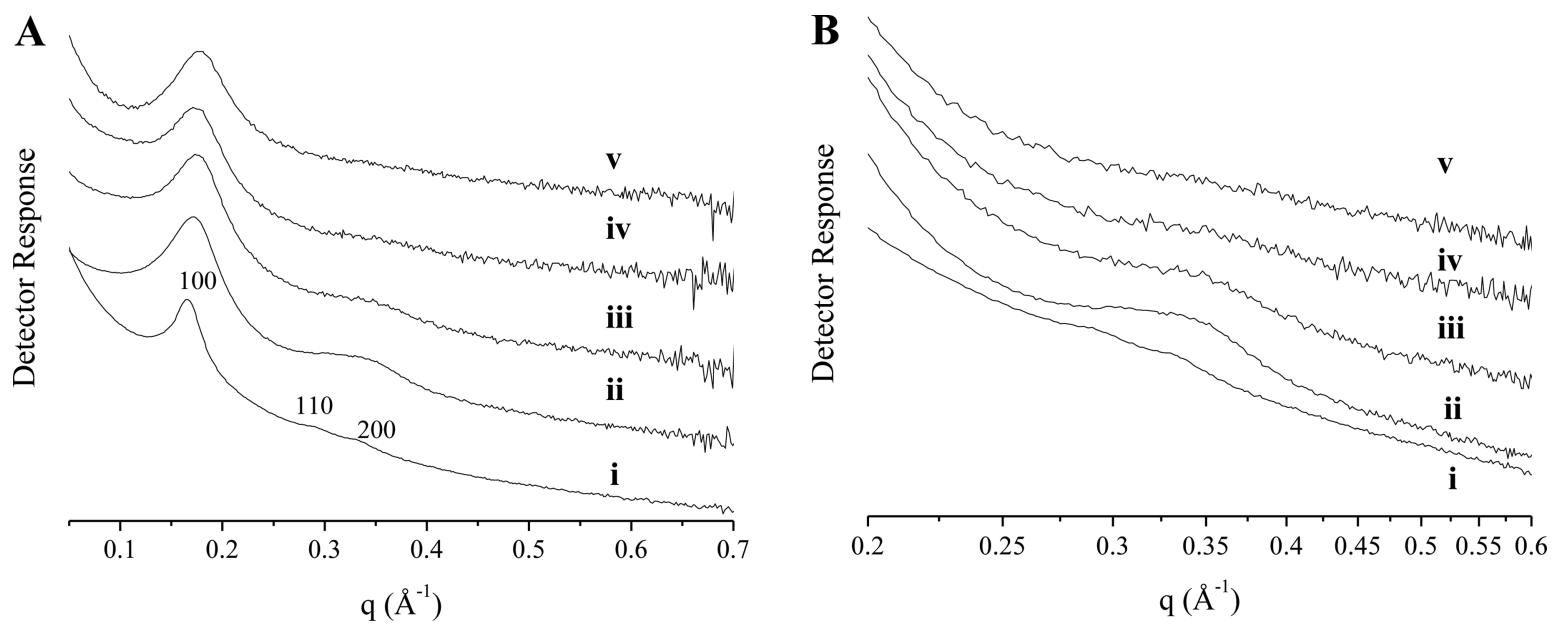

Figure 3. Small-angle X-ray scattering profiles for $1100 \mathrm{~nm}$ MSNs at AEAP3 reaction concentrations of (i) 0, (ii) 1.4, (iii) 2.9, (iv) 5.7, and (v) 11.5 $\mathrm{mM}$. The scattering profile is presented in (A), and an enlarged view of the $110 / 200$ scattering lines is displayed in (B).
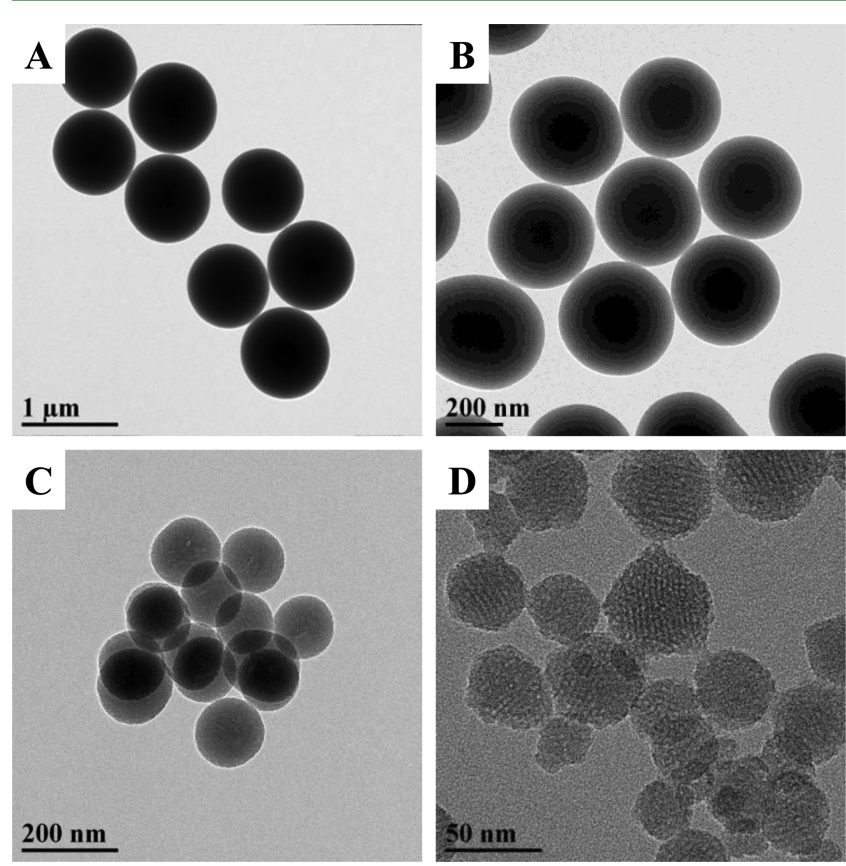

Figure 4. Transmission electron micrographs of (A) 1100, (B) 450, (C) 150, and (D) $30 \mathrm{~nm}$ AEAP3-modified mesoporous silica nanoparticles.

corresponding to reaction of the proton-labile $\mathrm{N}$-diazeniumdiolate with water to generate NO. ${ }^{53,54}$ Despite large total NO storage $\left(>0.8 \mu \mathrm{mol} \mathrm{mg}^{-1}\right)$ for all four particle systems, total NO storage $(p<0.01)$, NO release half-lives $(p<0.01)$, and release durations $(p=0.02)$ were unexpectedly diverse. The $1100 \mathrm{~nm}$ particles exhibited large NO storage $\left(1.41 \mu \mathrm{mol} \mathrm{mg}^{-1}\right)$ and rapid release $\left(t_{1 / 2}=25.6 \mathrm{~min}\right)$. Similarly, the $30 \mathrm{~nm} \mathrm{AEAP3/}$ NO particles released their total NO payload rapidly $\left(t_{1 / 2}=\right.$ $27.4 \mathrm{~min}$ ) but stored only a fraction of the NO measured for the $1100 \mathrm{~nm}$ particles $\left([\mathrm{NO}]_{\mathrm{t}}=0.88 \mu \mathrm{mol} \mathrm{mg}^{-1}\right)$. Although the $450 \mathrm{~nm}$ MSNs were characterized with low NO storage (0.82 $\left.\mu \mathrm{mol} \mathrm{mg}^{-1}\right)$, they were associated with the longest NO release half-life $(88.2 \mathrm{~min})$. Relative to the $1100 \mathrm{~nm} \mathrm{AEAP3/NO}$ particles, the $150 \mathrm{~nm}$ MSNs exhibited comparable NO storage $\left(1.30 \mu \mathrm{mol} \mathrm{mg}{ }^{-1}\right)$ and intermediate $\mathrm{NO}$ release rates $\left(t_{1 / 2}=\right.$ $41.9 \mathrm{~min})$.

The difference in $\mathrm{NO}$ release kinetics between particle systems was not anticipated as all particles were functionalized with the same $\mathrm{N}$-diazeniumdiolate precursor (AEAP3). For shedding further light on these effects, total NO release from the AEAP3/NO particles were compared to the degree of nitrogen incorporation measured by elemental analysis (Table 3) to determine $\mathrm{N}$-diazeniumdiolate formation efficiencies. As expected based on the NO release data, the $1100 \mathrm{~nm}$ MSNs exhibited the greatest NO donor formation efficiency (40.7\%), far greater than that reported by Carpenter et al. $(<27 \%) .{ }^{19}$ The $\mathrm{NO}$ donor formation efficiencies for the other three particle sizes were calculated at $23-31 \%$.

The wide range of NO release kinetics (half-lives of 27-88 min) and NO donor formation efficiencies (23-41\%) suggested additional factors were controlling $\mathrm{NO}$ release. One possible influence to NO release kinetics is particle size and the position of the $\mathrm{N}$-diazeniumdiolates within the pore network, which may affect NO donor accessibility by water and thus impact NO release kinetics. However, aminosilane ( $N$ -

\section{Table 3. Physicochemical Characterization of AEAP3-Functionalized MSNs of Varying Size ${ }^{a}$}

\begin{tabular}{|c|c|c|c|c|c|}
\hline geometric diameter $(\mathrm{nm})^{b}$ & $\mathrm{Z}$-average size $(\mathrm{nm})^{c}$ & $\mathrm{PDI}^{c}$ & nitrogen wt $\%^{d}$ & specific surface area $\left(\mathrm{m}^{2} \mathrm{~g}^{-1}\right)^{e}$ & pore width $(\AA)^{f}$ \\
\hline $36 \pm 8$ & $74 \pm 6$ & $0.12 \pm 0.06$ & $4.65 \pm 0.19$ & $210 \pm 40$ & $25.1 \pm 1.1$ \\
\hline $149 \pm 13$ & $223 \pm 17$ & $0.02 \pm 0.01$ & $5.91 \pm 0.13$ & $69 \pm 13$ & $24.8 \pm 0.6$ \\
\hline $450 \pm 50$ & $564 \pm 66$ & $0.04 \pm 0.02$ & $5.07 \pm 0.10$ & $68 \pm 20$ & $21.5 \pm 0.8$ \\
\hline $1110 \pm 210$ & $\mathrm{n} / \mathrm{a}^{g}$ & $\mathrm{n} / \mathrm{a}^{g}$ & $4.87 \pm 0.04$ & $3 \pm 1$ & $\mathrm{n} / \mathrm{a}^{h}$ \\
\hline
\end{tabular}

${ }^{a}$ Error bars represent standard deviation for $n \geq 3$ separate syntheses. ${ }^{b}$ Estimated using electron micrographs. ${ }^{c}$ Measured via dynamic light scattering. ${ }^{d}$ Nitrogen wt $\%$ measured by elemental analysis. ${ }^{e}$ Determined by BET analysis of the nitrogen sorption isotherms $\left(0.05 \leq \mathrm{p} / \mathrm{p}^{0} \leq 0.20\right)$. ${ }^{f}$ Calculated via BJH analysis of the nitrogen adsorption isotherm $\left(\mathrm{p} / \mathrm{p}^{0} \leq 0.60\right) .{ }^{g}$ Particle sedimentation interfered with DLS measurement. ${ }^{h}$ Pore width could not be calculated from the adsorption isotherm. 
Table 4. Chemiluminescent NO Release Measurements in Physiological Buffer (PBS, pH 7.4, $37^{\circ} \mathrm{C}$ ) from AEAP3/NO MSNs of Varying Size ${ }^{a}$

$\begin{array}{cccccc}\text { particle size }(\mathrm{nm}) & \left.[\mathrm{NO}]_{\max }(\mathrm{ppm} \mathrm{mg})^{-1}\right)^{b} & t_{1 / 2}(\mathrm{~min})^{c} & t_{\mathrm{d}}(\mathrm{h})^{d} & {[\mathrm{NO}]_{\mathrm{t}}\left(\mu \mathrm{mol} \mathrm{mg}^{-1}\right)^{e}} & N \text {-diazeniumdiolate formation efficiency }(\%)^{f} \\ 30 & 18.7 \pm 2.2 & 27.4 \pm 8.9 & 12.2 \pm 3.0 & 0.88 \pm 0.05 & 26.6 \pm 1.8 \\ 150 & 22.6 \pm 4.4 & 40.7 \pm 11.0 & 16.7 \pm 1.4 & 1.30 \pm 0.11 & 30.9 \pm 2.7 \\ 450 & 6.6 \pm 1.8 & 88.2 \pm 10.5 & 14.0 \pm 0.3 & 0.82 \pm 0.08 & 22.8 \pm 2.3 \\ 1100 & 32.8 \pm 9.8 & 25.6 \pm 5.0 & 11.1 \pm 0.7 & 1.41 \pm 0.19 & 40.7 \pm 5.2\end{array}$

${ }^{a}$ Error bars represent standard deviation for $n \geq 3$ separate syntheses. ${ }^{b}$ Maximum instantaneous NO concentration. ${ }^{c} \mathrm{Half}$-life of NO release. ${ }^{d} \mathrm{NO}$ release duration; time required for NO concentrations to reach $\leq 10 \mathrm{ppb} \mathrm{mg}^{-1}$. ${ }^{e}$ Total NO release. ${ }^{f}$ Calculated using total NO release and nitrogen wt \% determined by elemental analysis (Table 3) according to equation provided in the Supporting Information.
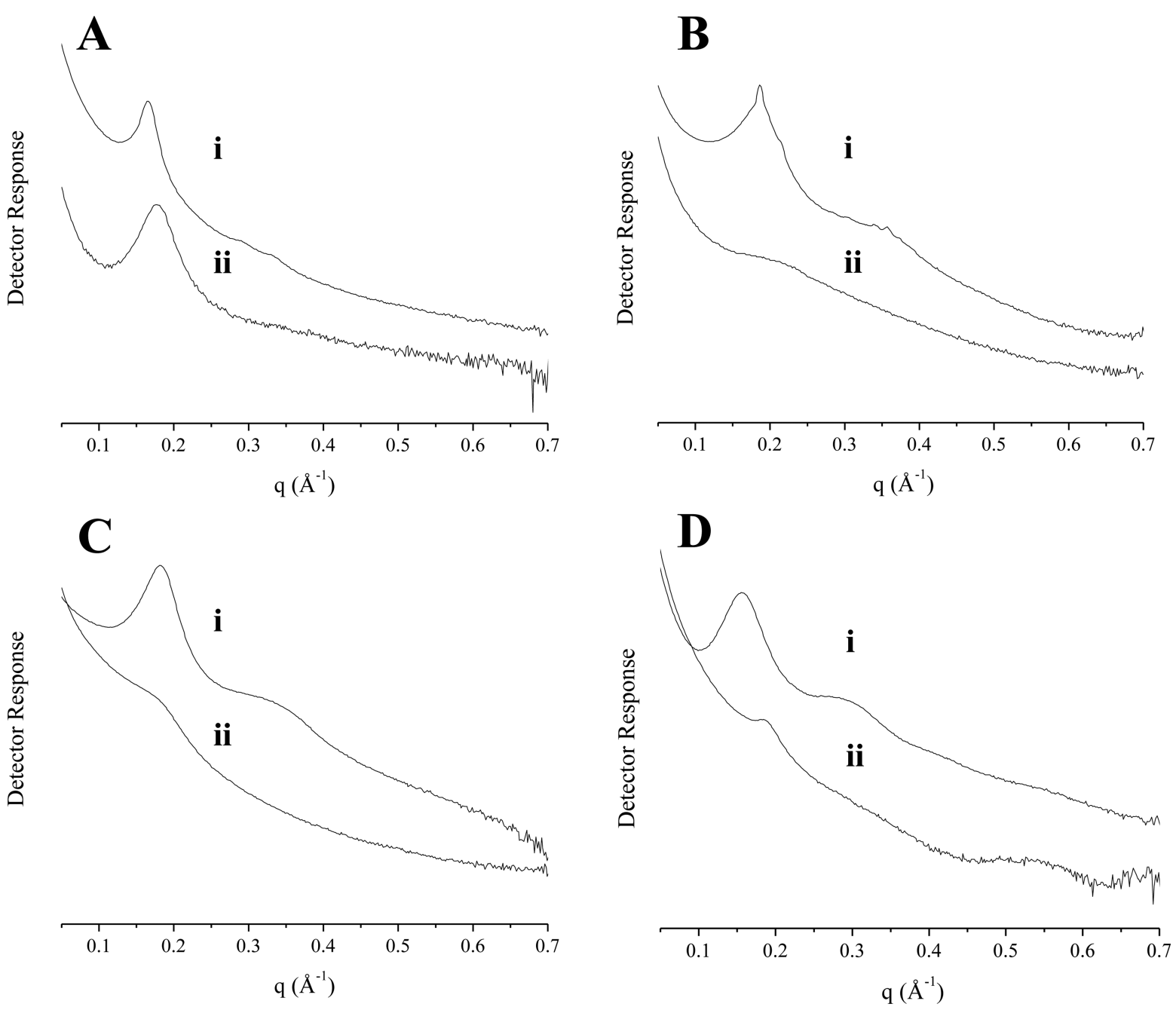

Figure 5. Small-angle X-ray scattering profiles for (A) 1100, (B) 450, (C) 150, and (D) $30 \mathrm{~nm}$ (i) bare and (ii) AEAP3-modified MSNs.

diazeniumdiolate) location alone does not account for the differences in NO release kinetics. For example, the largest particles, which could have NO donors buried as far as $0.5 \mu \mathrm{m}$ from their external surface, also had the shortest NO release half-life $\left(t_{1 / 2}=25.6 \mathrm{~min}\right)$ and duration $\left(t_{\mathrm{d}}=11.1 \mathrm{~h}\right)$. We hypothesized that the structure and ordering of the particle pore network may also affect NO release kinetics and partially account for these variations, particularly because a link between mesoscopic ordering and diffusion-based drug release has been demonstrated previously. ${ }^{55}$ For example, decreased organization may impede sodium methoxide access to pore-bound secondary amines, hindering $\mathrm{N}$-diazeniumdiolate formation. As an extension of the same logic, altered water diffusion into the pores would give rise to differences in NO release kinetics between AEAP3/NO MSNs of different sizes.

Small-angle X-ray scattering (SAXS) was used to assess pore ordering of the bare (Figure 5) and amine-modified (Figure S4) MSNs. As determined previously, the SAXS profile for the $1100 \mathrm{~nm}$ MSNs corresponded to a hexagonal lattice with modest ordering. In contrast to the observed MCM-41 structure for the largest particles, the scattering profile for the $30 \mathrm{~nm}$ MSNs alluded to an alternative mixed pore structure. Analysis of the smallest particles revealed three scattering peaks at $0.155,0.301$, and $0.552 \AA^{-1}$, which represented an intermediate to typical hexagonal and lamellar (layered) pore ordering. ${ }^{51,52}$ The appearance of the high angle reflection $\left(0.552 \AA^{-1}\right)$ was evidence for a significant degree of pore 

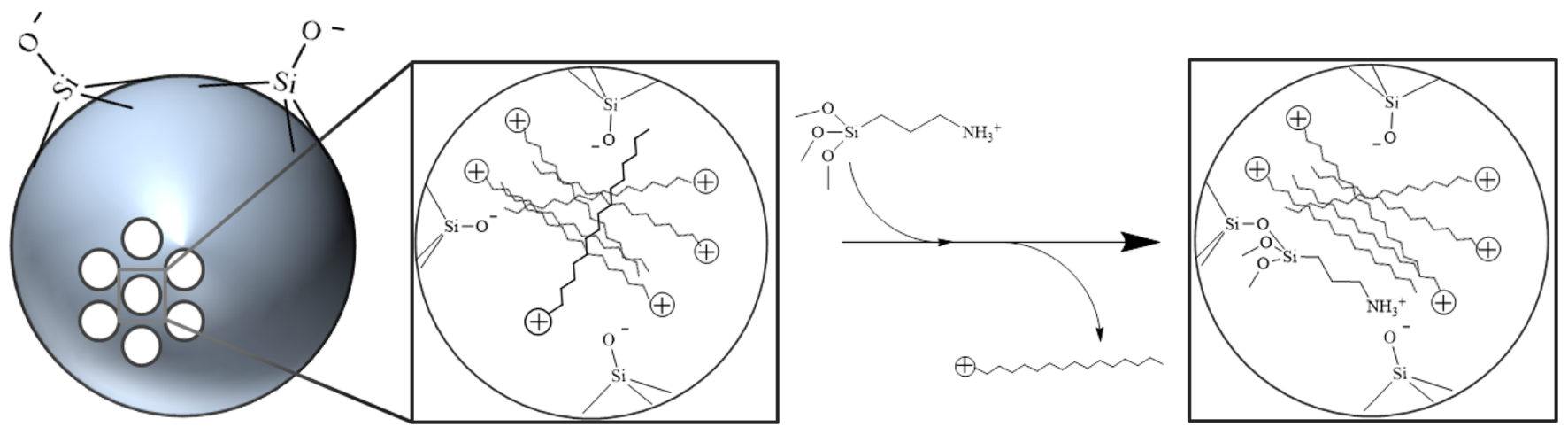

Figure 6. Proposed mechanism for MSN functionalization with aminosilanes. Positively charged aminosilanes undergo ion exchange with the template surfactant to stabilize anionic silanol species anchored to the mesopore walls.
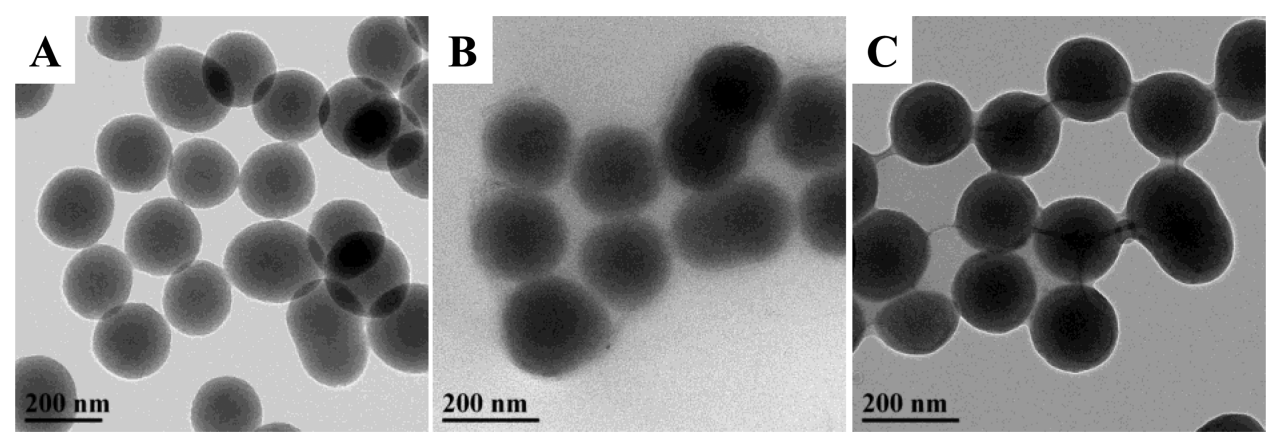

Figure 7. Transmission electron micrographs of $150 \mathrm{~nm}$ MSNs modified with (A) APTES, (B) BTMS, and (C) MPTMS. Particles in (A) exhibit smooth morphology, whereas agglomeration is observed in (B) and (C).

ordering; this peak is seldom observed for intermediate products. The electron micrographs for the $30 \mathrm{~nm}$ MSNs (Figure 4D) were in good agreement with the scattering data and provided further confirmation of a mixed pore structure. Xray scattering patterns obtained for the 150 and $450 \mathrm{~nm}$ particles were representative of a greater degree of pore disorder. Only a broad peak centered at $\sim 0.32 \AA^{-1}$ was observed in both scattering profiles (in addition to the 100 line at $\sim 0.17-0.19 \AA^{-1}$ ). The absence of an additional reflection confirmed mesophase irregularity for these particles. The scattering profiles for the 150 and $450 \mathrm{~nm}$ particles were characteristic of mesopore arrangements between hexagonal and lamellar structures. ${ }^{31}$ Although pore disorder was not as extensive for the $150 \mathrm{~nm}$ particles, the skewed peak at $\sim 0.18$ $\AA^{-1}$ for $450 \mathrm{~nm}$ MSNs suggested a more heterogeneous pore structure. In fact, the irregular peak shape was likely the superimposition of two separate low order reflections. Of note, the $\mathrm{X}$-ray scattering data for the amine-functionalized particles $1100 \mathrm{~nm}$ particles pointed to a slight loss in long-range ordering (Figure $5 \mathrm{~A}$ ) due to pore filling by AEAP3. ${ }^{56,57}$ Only broad reflections were evident in the scattering profiles for the 30, 150, and $450 \mathrm{~nm} \mathrm{AEAP3-modified} \mathrm{MSNs,} \mathrm{indicating} \mathrm{that}$ the aminosilane modification impacted the pore structures of these particle systems. Potential interference to pore structure determination by scattering contributions from the particles themselves (i.e., as monodisperse spheres) was unlikely because the raw scattering profile did not display typical interference fringes in the $0.01-0.1 \AA^{-1}$ region (Figure S4).

Particle X-ray scattering data provided insight into the relationship between MSN pore structure and NO release kinetics. The more ordered pore system (i.e., amine-modified $1100 \mathrm{~nm}$ particles) enables unrestricted (pore) access of sodium methoxide and water, resulting in large $\mathrm{NO}$ storage and rapid NO release, respectively. The 150 and $450 \mathrm{~nm}$ particles were capable of more sustained NO release, likely due to mesophase disruption with aminosilane addition. In contrast, the smallest $30 \mathrm{~nm}$ MSNs exhibited rapid NO release and lower NO storage $\left(0.88 \mu \mathrm{mol} \mathrm{mg}{ }^{-1}\right)$ despite collapse of the pore system. In this case, location of the $N$-diazeniumdiolates within the pore network and water access to the NO donors may more significantly affect NO release than particle mesoporosity.

Organosilane Modification. Although aminosilanes are highly reactive with the silanol groups that populate the surface of silica nanoparticles, they also readily undergo hydrolysis and autocondensation in aqueous conditions to form new, discrete entities. For this reason, addition of organosilane directly to the colloidal solution (i.e., particle reaction mixture) generally yields amorphous materials with heterogeneous functional group distribution. Postsynthetic grafting approaches thus require active steps for water removal from the reaction mixture to avoid undesirable particle agglomeration. ${ }^{38}$

In addition to anhydrous conditions, efficient particle modification is contingent upon successful removal of the pore-resident surfactant prior to reaction with aminosilanes, as the positively charged template molecule stabilizes the anionic surface silanols and may impede diffusion of external species into the pores. ${ }^{58,59}$ De Juan and co-workers previously exploited the stability of the surfactant CTAB template for selective derivatization of the outer and inner mesoporous silica surfaces using a step-by-step functionalization approach. ${ }^{60}$ In our study, the large degree of particle functionalization suggested that the aminosilanes likely displaced CTAB before undergoing autocondensation. We rationalized that this phenomenon might be due to an ion-exchange process between 
Table 5. Physicochemical Characterization of $30 \mathrm{~nm}$ NO-Releasing MSNs as a Function of Aminosilane Modification ${ }^{a}$

\begin{tabular}{|c|c|c|c|c|c|c|c|}
\hline \multirow[b]{2}{*}{ aminosilane modification } & \multicolumn{4}{|c|}{ particle characterization } & \multicolumn{3}{|c|}{ NO release } \\
\hline & geometric size $(\mathrm{nm})^{b}$ & Z-average size $(\mathrm{nm})^{c}$ & $\mathrm{PDI}^{c}$ & nitrogen wt $\%^{d}$ & $t_{1 / 2}(\min )^{e}$ & $\overline{t_{\mathrm{d}}(\mathrm{h})^{f}}$ & {$[\mathrm{NO}]_{\mathrm{t}}\left(\mu \mathrm{mol} \mathrm{mg}^{-1}\right)^{g}$} \\
\hline MAP3 & $37.1 \pm 8.3$ & $91.2 \pm 8.8$ & $0.16 \pm 0.05$ & $3.26 \pm 0.15$ & $2.2 \pm 0.2$ & $1.8 \pm 0.4$ & $1.39 \pm 0.10$ \\
\hline AHAP3 & $42.3 \pm 8.1$ & $131.8 \pm 9.4$ & $0.17 \pm 0.04$ & $4.18 \pm 0.05$ & $4.7 \pm 2.3$ & $5.9 \pm 0.2$ & $1.20 \pm 0.10$ \\
\hline AEAP3 & $35.7 \pm 8.1$ & $74.1 \pm 6.2$ & $0.12 \pm 0.06$ & $4.65 \pm 0.19$ & $27.4 \pm 8.9$ & $12.2 \pm 3.0$ & $0.88 \pm 0.05$ \\
\hline DET3 & $34.5 \pm 7.6$ & $83.0 \pm 7.6$ & $0.17 \pm 0.04$ & $5.60 \pm 0.31$ & $47.0 \pm 11.9$ & $33.2 \pm 4.7$ & $1.37 \pm 0.19$ \\
\hline
\end{tabular}

${ }^{a}$ Error bars represent standard deviation for $n \geq 3$ separate syntheses. ${ }^{b}$ Estimated using electron micrographs. ${ }^{c}$ Measured via dynamic light scattering. ${ }^{d}$ Nitrogen wt $\%$ measured via elemental analysis. ${ }^{e}$ Half-life of NO release. ${ }^{f} \mathrm{NO}$ release duration; time required for NO concentrations to reach $\leq 10 \mathrm{ppb} \mathrm{mg}^{-1}{ }^{g}$ Total NO release.

the surfactant and protonated aminosilanes (Figure 6). Both Dai et al. ${ }^{61}$ and Bourlinos et al. ${ }^{62}$ have described ion exchange between cationic species (metal ions and aminosilanes, respectively) and the $\mathrm{CTAB}$ template as a method for particle modification. In both cases, the uncalcined (i.e., CTABcontaining) silica was modified in a separate reaction rather than a one-step procedure.

We sought to verify that only MSN modification with cationic species would preserve particle morphology. Using the $150 \mathrm{~nm}$ particle system, the MSNs were functionalized with either isobutyl(trimethoxy)silane (BTMS) or (3mercaptopropyl)trimethoxysilane (MPTMS) at concentrations equal to those employed for the $150 \mathrm{~nm}$ AEAP3 particles. As the colloidal solution is formed under basic conditions, the BTMS alkyl groups remain neutral, whereas a significant fraction of the MPTMS side chains would exist as the anionic thiolate species $\left(\mathrm{p} K_{\mathrm{a}} \sim 10\right)^{63,64}$ in both cases preventing ion exchange. 3-Aminopropyltriethoxysilane (APTES) was used as a positive control, as APTES is similar in size to BTMS and MPTMS but should undergo efficient ion exchange with CTAB due to the presence of a basic primary amine.

The morphology of the $150 \mathrm{~nm}$ APTES, BTMS, and MPTMS particles was examined using transmission electron microscopy (Figure 7). As expected, $150 \mathrm{~nm}$ particles functionalized with APTES exhibited uniform morphology with excellent sphericity consistent with that of the $150 \mathrm{~nm}$ AEAP3 MSNs. Evaluation of aqueous APTES particle suspensions by DLS indicated that the monodispersity of the particles $(\mathrm{PDI}=0.03 \pm 0.02)$ was preserved upon aminosilane modification. In contrast, undesirable silane bridging and particle agglomeration were evident in electron micrographs of the MPTMS- and BTMS-modified particles. A significant increase in the carbon wt \% (measured by elemental analysis; Table S2) for all particle systems indicated that the silanes were incorporated into the final product. The morphological differences between particles observed using TEM were due to reaction with organosilanes. Although this data does not exclude the possibility of alternative reaction mechanisms, the particle analyses presented provide clear support of ion exchange reactions between cationic organosilanes and CTAB.

Aminosilane Modification and Nitric Oxide-Release Kinetics. As the structure of the precursor amine for $\mathrm{N}$ diazeniumdiolate formation influences NO release kinetics from both small molecules ${ }^{11}$ and nonporous silica particles, ${ }^{27}$ we sought to alter the NO release kinetics from the MSNs using different organosilanes. The $30 \mathrm{~nm}$ particle system was systematically modified with several aminosilanes, including AHAP3, DET3, and MAP3.

The characterization of the precursor- and NO donormodified MSNs is provided in Table 5. Both the geometric size $(\sim 35-43 \mathrm{~nm})$ and PDI $(<0.20)$ of the particles remained approximately constant $(p>0.5)$, indicating that the small particle size and monodispersity were conserved during the chemical modification procedure regardless of aminosilane type. The measured hydrodynamic diameter (Z-average size) of each particle system $(75-130 \mathrm{~nm})$ was dependent on the composition of the aminosilane but agreed well with the corresponding geometric sizes. Nitrogen content for each MSN system varied expectedly based on the elemental composition of the aminosilane reactant. Particles functionalized with the monoamine MAP3 incorporated the least amount of nitrogen $(3.26 \%)$, whereas the nitrogen wt \% was greatest for the triamine DET3 modification (5.60\%). Intermediate nitrogen content was measured for MSNs with attached AHAP3 (4.18\%) and AEAP3 (4.65\%), which are diaminosilanes of differing carbon content.

The large degree of aminosilane incorporation translated to excellent particle NO storage, exceeding $1.00 \mu \mathrm{mol} \mathrm{mg}^{-1}$ for all particle systems tested except AEAP3/NO. Lower total NO storage for AEAP3/NO was expected based on previous results, as intramolecular hydrogen bonding between the side chain amines hinders $\mathrm{N}$-diazeniumdiolate formation. ${ }^{11,65}$ Although these interactions are also possible for DET3, the presence of two secondary amines resulted in greater $\mathrm{NO}$ storage. As anticipated, the MSN NO release kinetics were markedly different between the four particle systems $(p<0.01)$. The $\mathrm{MAP} 3 / \mathrm{NO}$ and AHAP3/NO particles were characterized with rapid initial NO release $\left(t_{1 / 2}\right.$ of 2.2 and $4.7 \mathrm{~min}$, respectively), whereas the NO release for the AEAP3/NO and DET3/NO particles was more sustained $\left(t_{1 / 2}\right.$ of 27.4 and $47.0 \mathrm{~min}$, respectively) as a result of $N$-diazeniumdiolate charge stabilization by neighboring protonated amines (Table 5; Figure S5). ${ }^{11,65}$ The NO release durations covered $\sim 2-33 \mathrm{~h}$, rendering these particles especially useful as NO delivery vehicles where tuning NO release kinetics is critical to efficacy. ${ }^{9}$

It should be noted that others have reported macromolecular NO donor scaffolds with total NO release values exceeding $\sim 1.5 \mu \mathrm{mol} \mathrm{mg}{ }^{-1}$. For example, several porous metal organic frameworks (MOFs) have been developed with NO storage approaching 1-7 $\mu \mathrm{mol} \mathrm{mg}^{-1}$ through direct adsorption of $\mathrm{NO}$ gas. ${ }^{66}$ However, NO release from MOFs is generally rapid, restricting their utility to applications in which the NO donor scaffold is in contact with humidified gas. Both dendrimers ${ }^{67}$ and silica particles ${ }^{24}$ modified with $S$-nitrosothiol (RSNO) NO donors also exhibit large NO payloads ( 2 and $4 \mu \mathrm{mol} \mathrm{mg}^{-1}$, respectively) with $\mathrm{NO}$ release durations exceeding 2 days in deoxygenated PBS buffer. Unfortunately, RSNOs are unstable NO donors, readily decomposing to yield NO under multiple triggers (e.g., light, heat, reaction with $\mathrm{Cu}^{+}$ions or ascorbate). $S$-nitrosothiol stability is further compromised in the presence of oxygen, where reaction with NO produces nitrogen trioxide, an RSNO-reactive species that initiates excessively rapid 
autocatalytic decomposition. ${ }^{68}$ In contrast, $N$-diazeniumdiolate NO donors alleviate the issue of uncontrolled decomposition, liberating $\mathrm{NO}$ at rates dependent on both the structure of the aminosilane and the solution $\mathrm{pH}$. Although poor $\mathrm{NO}$ storage and difficult synthetic procedures have traditionally excluded $N$ diazeniumdiolate-modified macromolecular NO donors from therapeutic evaluation, the preparation of NO-releasing mesoporous silica particles was achieved in high yields via ion exchange reactions. Excellent NO storage and diverse $\mathrm{NO}$ release kinetics from the MSNs were obtained by simply changing the aminosilane without further synthetic optimization, representing a significant improvement to $\mathrm{N}$-diazeniumdiolate-based NO delivery vehicles.

\section{CONCLUSIONS}

Nitric oxide-releasing mesoporous silica nanoparticles with a range of sizes $(30,150,450$, and $1100 \mathrm{~nm})$ were successfully prepared using a straightforward aminosilane-CTAB ion exchange approach. The resulting MSNs were well-defined and exhibited a large degree of surface modification, which translated to competitive NO storage with other macromolecular NO donors (e.g., MOFs, RSNOs). Particle NO storage and release kinetics were dependent on both the structure of the pores and the identity of the precursor aminosilane. This report is the first to detail the dependence of NO release kinetics on the architectural properties of mesoporous silica. Further understanding of the intricate relationships between pore ordering and NO release kinetics remains an exciting area of research, as controlled mesophase structure would also provide an additional degree of control in macromolecular NO donor design. Moreover, the ability to easily modify the MSNs with different aminosilanes enabled tuning of $\mathrm{NO}$ release kinetics without sacrificing control over either total NO storage or particle size.

\section{ASSOCIATED CONTENT}

\section{S Supporting Information}

The Supporting Information is available free of charge on the ACS Publications website at DOI: 10.1021/acsami.5b10942.

Additional electron micrographs and NO release properties of the $1100 \mathrm{~nm}$ AEAP3-modified MSNs, nitrogen sorption isotherms for $1100 \mathrm{~nm}$ AEAP3 particles, ${ }^{29} \mathrm{Si}$ NMR spectra for AEAP3-modified MSNs, SAXS profiles for AEAP3-modified MSNs, and elemental analysis of $150 \mathrm{~nm}$ APTES, BTMS, and MPTMS particles (PDF)

\section{AUTHOR INFORMATION}

\section{Corresponding Author}

*E-mail: schoenfisch@unc.edu.

\section{Funding}

This research was supported by the National Science Foundation (DMR 1104892) and the National Institutes of Health (DK108318). R.J.S. thankfully acknowledges a John Motley Morehead graduate fellowship from the Royster Society of Fellows at the University of North Carolina-Chapel Hill.

\section{Notes}

The authors declare the following competing financial interest: Mark Schoenfisch is a cofounder, a member of the board of directors, and maintains a financial interest in Novan Therapeutics, Inc. Novan is commercializing macromolecular nitric oxide storage and release vehicles for dermatological indications.

\section{ACKNOWLEDGMENTS}

The authors express their gratitude to Dr. Amar Kumbhar at the UNC Chapel Hill Analytical and Nanofabrication Laboratory (CHANL) for expertise and assistance with the TEM. We acknowledge Dr. Marc ter Horst for assistance with solid-state ${ }^{29} \mathrm{Si}$ NMR. We also thank Dr. Mark Walters and Jimmy Thostenson at Duke University's Shared Materials Instrumentation Facility (SMIF) for their technical help with the Ganesha SAXS system.

\section{REFERENCES}

(1) Cooke, J. P. NO and Angiogenesis. Atheroscler. Suppl. 2003, 4, 53-60.

(2) Ignarro, L. J.; Buga, G. M.; Wood, K. S.; Byrns, R. E.; Chaudhuri, G. Endothelium-Derived Relaxing Factor Produced and Released from Artery and Vein Is Nitric Oxide. Proc. Natl. Acad. Sci. U. S. A. 1987, 84, 9265-9269.

(3) Luo, J.-d.; Chen, A. F. Nitric Oxide: A Newly Discovered Function on Wound Healing. Acta Pharmacol. Sin. 2005, 26, 259-264.

(4) Schwentker, A.; Vodovotz, Y.; Weller, R.; Billiar, T. R. Nitric Oxide and Wound Repair: Role of Cytokines? Nitric Oxide 2002, 7, 110.

(5) Bogdan, C. Nitric Oxide and the Immune Response. Nat. Immunol. 2001, 2, 907-916.

(6) MacMicking, J.; Xie, Q.-w.; Nathan, C. Nitric Oxide and Macrophage Function. Annu. Rev. Immunol. 1997, 15, 323-350.

(7) Kiss, J. P. Role of Nitric Oxide in the Regulation of Monoaminergic Neurotransmission. Brain Res. Bull. 2000, 52, 459466.

(8) Hetrick, E. M.; Schoenfisch, M. H. Analytical Chemistry of Nitric Oxide. Annu. Annu. Rev. Anal. Chem. 2009, 2, 409-433.

(9) Carpenter, A. W.; Schoenfisch, M. H. Nitric Oxide Release Part Ii. Therapeutic Applications. Chem. Soc. Rev. 2012, 41, 3742-3752.

(10) Hetrick, E. M.; Shin, J. H.; Stasko, N. A.; Johnson, C. B.; Wespe, D. A.; Holmuhamedov, E.; Schoenfisch, M. H. Bactericidal Efficacy of Nitric Oxide-Releasing Silica Nanoparticles. ACS Nano 2008, 2, 235246.

(11) Keefer, L. K. Fifty Years of Diazeniumdiolate Research. From Laboratory Curiosity to Broad-Spectrum Biomedical Advances. ACS Chem. Biol. 2011, 6, 1147-1155.

(12) Lu, Y.; Shah, A.; Hunter, R. A.; Soto, R. J.; Schoenfisch, M. H. SNitrosothiol-Modified Nitric Oxide-Releasing Chitosan Oligosaccharides as Antibacterial Agents. Acta Biomater. 2015, 12, 62-69.

(13) Lu, Y.; Slomberg, D. L.; Shah, A.; Schoenfisch, M. H. Nitric Oxide-Releasing Amphiphilic Poly(Amidoamine) (Pamam) Dendrimers as Antibacterial Agents. Biomacromolecules 2013, 14, 3589-98.

(14) Lu, Y.; Sun, B.; Li, C.; Schoenfisch, M. H. Structurally Diverse Nitric Oxide-Releasing Poly(Propylene Imine) Dendrimers. Chem. Mater. 2011, 23, 4227-4233.

(15) Stasko, N. A.; Schoenfisch, M. H. Dendrimers as a Scaffold for Nitric Oxide Release. J. Am. Chem. Soc. 2006, 128, 8265-8271.

(16) Polizzi, M. A.; Stasko, N. A.; Schoenfisch, M. H. Water-Soluble Nitric Oxide-Releasing Gold Nanoparticles. Langmuir 2007, 23, 4938-4943.

(17) Rothrock, A. R.; Donkers, R. L.; Schoenfisch, M. H. Synthesis of Nitric Oxide-Releasing Gold Nanoparticles. J. Am. Chem. Soc. 2005, 127, 9362-9363.

(18) Backlund, C. J.; Sergesketter, A. R.; Offenbacher, S.; Schoenfisch, M. H. Antibacterial Efficacy of Exogenous Nitric Oxide on Periodontal Pathogens. J. Dent. Res. 2014, 93, 1089-1094.

(19) Carpenter, A. W.; Slomberg, D. L.; Rao, K. S.; Schoenfisch, M. $\mathrm{H}$. Influence of Scaffold Size on Bactericidal Activity of Nitric OxideReleasing Silica Nanoparticles. ACS Nano 2011, 5, 7235-7244.

(20) Carpenter, A. W.; Worley, B. V.; Slomberg, D. L.; Schoenfisch, M. H. Dual Action Antimicrobials: Nitric Oxide Release from Quaternary Ammonium-Functionalized Silica Nanoparticles. Biomacromolecules 2012, 13, 3334-3342. 
(21) Slomberg, D. L.; Lu, Y.; Broadnax, A. D.; Hunter, R. A.; Carpenter, A. W.; Schoenfisch, M. H. Role of Size and Shape on Biofilm Eradication for Nitric Oxide-Releasing Silica Nanoparticles. ACS Appl. Mater. Interfaces 2013, 5, 9322-9329.

(22) Frost, M. C.; Meyerhoff, M. E. Synthesis, Characterization, and Controlled Nitric Oxide Release from S-Nitrosothiol-Derivatized Fumed Silica Polymer Filler Particles. J. Biomed. Mater. Res., Part A 2005, 72A, 409-419.

(23) Kafshgari, M. H.; Cavallaro, A.; Delalat, B.; Harding, F. J.; McInnes, S. J. P.; Mäkilä, E.; Salonen, J.; Vasilev, K.; Voelcker, N. H. Nitric Oxide-Releasing Porous Silicon Nanoparticles. Nanoscale Res. Lett. 2014, 9, 333.

(24) Riccio, D. A.; Nugent, J. L.; Schoenfisch, M. H. Stöber Synthesis of Nitric Oxide-Releasing S-Nitrosothiol-Modified Silica Particles. Chem. Mater. 2011, 23, 1727-1735.

(25) Zhang, H.; Annich, G. M.; Miskulin, J.; Stankiewicz, K.; Osterholzer, K.; Merz, S. I.; Bartlett, R. H.; Meyerhoff, M. E. Nitric Oxide-Releasing Fumed Silica Particles: Synthesis, Characterization, and Biomedical Application. J. Am. Chem. Soc. 2003, 125, 5015-5024.

(26) Lu, Y.; Slomberg, D. L.; Sun, B.; Schoenfisch, M. H. Shape- and Nitric Oxide Flux-Dependent Bactericidal Activity of Nitric OxideReleasing Silica Nanorods. Small 2013, 9, 2189-2198.

(27) Backlund, C. J.; Worley, B. V.; Sergesketter, A. R.; Schoenfisch, M. H. Kinetic-Dependent Killing of Oral Pathogens with Nitric Oxide. J. Dent. Res. 2015, 94, 1092.

(28) Koh, A.; Riccio, D. A.; Sun, B.; Carpenter, A. W.; Nichols, S. P.; Schoenfisch, M. H. Fabrication of Nitric Oxide-Releasing Polyurethane Glucose Sensor Membranes. Biosens. Bioelectron. 2011, 28, 17-24.

(29) Soto, R. J.; Privett, B. J.; Schoenfisch, M. H. In Vivo Analytical Performance of Nitric Oxide-Releasing Glucose Biosensors. Anal. Chem. 2014, 86, 7141-7149.

(30) Beck, J. S.; Vartuli, J. C.; Roth, W. J.; Leonowicz, M. E.; Kresge, C. T.; Schmitt, K. D.; Chu, C. T. W.; Olson, D. H.; Sheppard, E. W. A New Family of Mesoporous Molecular Sieves Prepared with Liquid Crystal Templates. J. Am. Chem. Soc. 1992, 114, 10834-10843.

(31) Huo, Q.; Margolese, D. I.; Stucky, G. D. Surfactant Control of Phases in the Synthesis of Mesoporous Silica-Based Materials. Chem. Mater. 1996, 8, 1147-1160.

(32) Huh, S.; Wiench, J. W.; Yoo, J.-C.; Pruski, M.; Lin, V. S. Y. Organic Functionalization and Morphology Control of Mesoporous Silicas Via a Co-Condensation Synthesis Method. Chem. Mater. 2003, $15,4247-4256$.

(33) Burleigh, M. C.; Markowitz, M. A.; Spector, M. S.; Gaber, B. P. Direct Synthesis of Periodic Mesoporous Organosilicas: Functional Incorporation by Co-Condensation with Organosilanes. J. Phys. Chem. B 2001, 105, 9935-9942.

(34) Trewyn, B. G.; Slowing, I. I.; Giri, S.; Chen, H.-T.; Lin, V. S. Y. Synthesis and Functionalization of a Mesoporous Silica Nanoparticle Based on the Sol-Gel Process and Applications in Controlled Release. Acc. Chem. Res. 2007, 40, 846-853.

(35) Chen, J.; Li, Q.; Xu, R.; Xiao, F. Distinguishing the Silanol Groups in the Mesoporous Molecular Sieve Mcm-41. Angew. Chem., Int. Ed. Engl. 1996, 34, 2694-2696.

(36) Gartmann, N.; Brühwiler, D. Controlling and Imaging the Functional-Group Distribution on Mesoporous Silica. Angew. Chem., Int. Ed. 2009, 48, 6354-6356.

(37) Sharma, K. K.; Anan, A.; Buckley, R. P.; Ouellette, W.; Asefa, T. Toward Efficient Nanoporous Catalysts: Controlling Site-Isolation and Concentration of Grafted Catalytic Sites on Nanoporous Materials with Solvents and Colorimetric Elucidation of Their Site-Isolation. J. Am. Chem. Soc. 2008, 130, 218-228.

(38) Bruhwiler, D. Postsynthetic Functionalization of Mesoporous Silica. Nanoscale 2010, 2, 887-892.

(39) Lang, N.; Tuel, A. A Fast and Efficient Ion-Exchange Procedure to Remove Surfactant Molecules from Mcm-41 Materials. Chem. Mater. 2004, 16, 1961-1966.

(40) Kecht, J.; Bein, T. Oxidative Removal of Template Molecules and Organic Functionalities in Mesoporous Silica Nanoparticles by
Peroxide Treatment. Microporous Mesoporous Mater. 2008, 116, 123130.

(41) Webb, P. A.; Orr, C. Analytical Methods in Fine Particle Technology. Micromeritics Instrument Corporation: Norcross, GA, 1997.

(42) Sing, K. S. W.; Everett, D. H.; Haul, R. A. W.; Moscou, L.; Pierotti, R. A.; Rouquerol, J.; Siemieniewska, T. Reporting Physisorption Data for Gas/Solid Systems with Special Reference to the Determination of Surface Area and Porosity. Pure Appl. Chem. $1985,57,603-613$.

(43) Nooney, R. I.; Thirunavukkarasu, D.; Chen, Y.; Josephs, R.; Ostafin, A. E. Synthesis of Nanoscale Mesoporous Silica Spheres with Controlled Particle Size. Chem. Mater. 2002, 14, 4721-4728.

(44) Lee, C.-H.; Lo, L.-W.; Mou, C.-Y.; Yang, C.-S. Synthesis and Characterization of Positive-Charge Functionalized Mesoporous Silica Nanoparticles for Oral Drug Delivery of an Anti-Inflammatory Drug. Adv. Funct. Mater. 2008, 18, 3283-3292.

(45) Pauly, T. R. Pinnavaia, T. J. Pore Size Modification of Mesoporous Hms Molecular Sieve Silicas with Wormhole Framework Structures. Chem. Mater. 2001, 13, 987-993.

(46) Kruk, M.; Jaroniec, M. Gas Adsorption Characterization of Ordered Organic-Inorganic Nanocomposite Materials. Chem. Mater. 2001, 13, 3169-3183.

(47) Albert, K.; Bayer, E. Characterization of Bonded Phases by Solid-State Nmr Spectroscopy. J. Chromatogr. A 1991, 544, 345-370.

(48) Kobler, J.; Möller, K.; Bein, T. Colloidal Suspensions of Functionalized Mesoporous Silica Nanoparticles. ACS Nano 2008, 2, 791-799.

(49) Smarsly, B.; Groenewolt, M.; Antonietti, M. Saxs Analysis of Mesoporous Model Materials: A Validation of Data Evaluation Techniques to Characterize Pore Size, Shape, Surface Area, and Curvature of the Interface. In Scattering Methods and the Properties of Polymer Materials; Springer: Berlin Heidelberg, 2005; Vol. 130, pp $105-113$.

(50) Kresge, C. T.; Leonowicz, M. E.; Roth, W. J.; Vartuli, J. C.; Beck, J. S. Ordered Mesoporous Molecular Sieves Synthesized by a LiquidCrystal Template Mechanism. Nature 1992, 359, 710-712.

(51) Huo, Q.; Margolese, D. I.; Ciesla, U.; Demuth, D. G.; Feng, P.; Gier, T. E.; Sieger, P.; Firouzi, A.; Chmelka, B. F. Organization of Organic Molecules with Inorganic Molecular Species into Nanocomposite Biphase Arrays. Chem. Mater. 1994, 6, 1176-1191.

(52) Beck, J. S.; Vartuli, J. C.; Kennedy, G. J.; Kresge, C. T.; Roth, W. J.; Schramm, S. E. Molecular or Supramolecular Templating: Defining the Role of Surfactant Chemistry in the Formation of Microporous and Mesoporous Molecular Sieves. Chem. Mater. 1994, 6, 1816-1821.

(53) Davies, K. M.; Wink, D. A.; Saavedra, J. E.; Keefer, L. K. Chemistry of the Diazeniumdiolates. 2. Kinetics and Mechanism of Dissociation to Nitric Oxide in Aqueous Solution. J. Am. Chem. Soc. 2001, 123, 5473-5481.

(54) Coneski, P. N.; Schoenfisch, M. H. Nitric Oxide Release Part Iii. Measurement and Reporting. Chem. Soc. Rev. 2012, 41, 3753-3758.

(55) Andersson, J.; Rosenholm, J.; Areva, S.; Lindén, M. Influences of Material Characteristics on Ibuprofen Drug Loading and Release Profiles from Ordered Micro- and Mesoporous Silica Matrices. Chem. Mater. 2004, 16, 4160-4167.

(56) Lai, C.-Y.; Trewyn, B. G.; Jeftinija, D. M.; Jeftinija, K.; Xu, S.; Jeftinija, S.; Lin, V. S. Y. A Mesoporous Silica Nanosphere-Based Carrier System with Chemically Removable Cds Nanoparticle Caps for Stimuli-Responsive Controlled Release of Neurotransmitters and Drug Molecules. J. Am. Chem. Soc. 2003, 125, 4451-4459.

(57) Winkler, H.; Birkner, A.; Hagen, V.; Wolf, I.; Schmechel, R.; Seggern, H. v.; Fischer, R. A. Quantum-Confined Gallium Nitride in Mcm-41. Adv. Mater. 1999, 11, 1444-1448.

(58) Cheng, K.; Landry, C. C. Diffusion-Based Deprotection in Mesoporous Materials: A Strategy for Differential Functionalization of Porous Silica Particles. J. Am. Chem. Soc. 2007, 129, 9674-9685.

(59) Kecht, J.; Schlossbauer, A.; Bein, T. Selective Functionalization of the Outer and Inner Surfaces in Mesoporous Silica Nanoparticles. Chem. Mater. 2008, 20, 7207-7214. 
(60) de Juan, F.; Ruiz-Hitzky, E. Selective Functionalization of Mesoporous Silica. Adv. Mater. 2000, 12, 430-432.

(61) Dai, S.; Shin, Y.; Ju, Y.; Burleigh, M. C.; Lin, J. S.; Barnes, C. E.; Xue, Z. A New Methodology to Functionalize Surfaces of Ordered Mesoporous Materials Based on Ion Exchange Reactions. Adv. Mater. 1999, 11, 1226-1230.

(62) Bourlinos, A. B.; Karakostas, T.; Petridis, D. Side Chain" Modification of Mcm-41 Silica through the Exchange of the Surfactant Template with Charged Functionalized Organosiloxanes: An Efficient Route to Valuable Reconstructed Mcm-41 Derivatives. J. Phys. Chem. B 2003, 107, 920-925.

(63) Dance, I. G. The Structural Chemistry of Metal Thiolate Complexes. Polyhedron 1986, 5, 1037-1104.

(64) Son, D.; Wolosiuk, A.; Braun, P. V. Double Direct Templated Hollow Zns Microspheres Formed on Chemically Modified Silica Colloids. Chem. Mater. 2009, 21, 628-634.

(65) Riccio, D. A.; Schoenfisch, M. H. Nitric Oxide Release Part I. Macromolecular Scaffolds. Chem. Soc. Rev. 2012, 41, 3731-3741.

(66) Wheatley, P. S.; Butler, A. R.; Crane, M. S.; Fox, S.; Xiao, B.; Rossi, A. G.; Megson, I. L.; Morris, R. E. No-Releasing Zeolites and Their Antithrombotic Properties. J. Am. Chem. Soc. 2006, 128, 502-9.

(67) Stasko, N. A.; Fischer, T. H.; Schoenfisch, M. H. S-NitrosothiolModified Dendrimers as Nitric Oxide Delivery Vehicles. Biomacromolecules 2008, 9, 834-841.

(68) Grossi, L.; Montevecchi, P. C. A Kinetic Study of S-Nitrosothiol Decomposition. Chem. - Eur. J. 2002, 8, 380-387. 